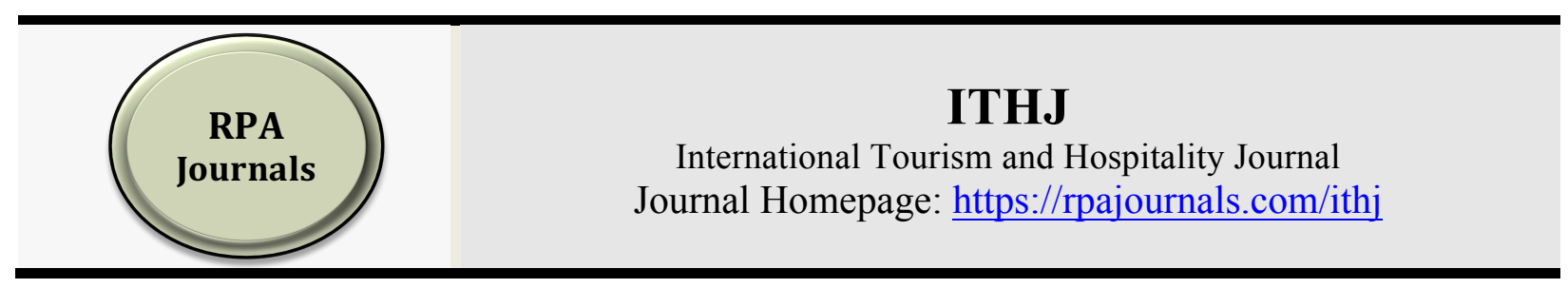

\title{
Perceived Effects of Climate Change on Tourism Sustainability in Maasai Mara National Game Reserve, Kenya
}

\author{
Laban Kipkemoi Rotich*1 \\ Richard Ogola Belle Makopondo ${ }^{2}$ \\ Nehemia Kiprop Kiprutto $^{3}$ \\ Davis Wekesa Barasa ${ }^{4}$ \\ The Technical University of Kenya ${ }^{1,2,4}$ \\ Moi University, Kenya ${ }^{3}$
}

\begin{abstract}
Nature based tourism industry is undoubtedly not immune to climatic changes. The climatic changes are due to natural causes but others are attributed to human activities. The purpose of the study was to determine the effects of climate change on tourism sustainability in Maasai Mara National Game Reserve (MMNGR), Kenya. The study adopts explanatory research design. The sample size was 507 respondents comprising of 399 households, 90 tourists and 18 experts selected by simple random sampling, convenience sampling and snowball sampling respectively. Structured questionnaires collected data from the host community which was analyzed using Pearson product moment of correlation, linear and multiple regressions. Data analyses were done through quantitative techniques of descriptive and inferential statistics with the aid of SPSS V.23. Results indicated that there is a positive significant relationship between climate change and tourism sustainability in MMNGR $(\beta 1=0.818$ and $p<0.05)$. Despite modest adaptive capacity to climate change effects, the study raises urgent interventions for the tourism industry stakeholders on rainfall and temperature variations that positively contribute to influence the decline in wildlife populations that impedes sustainability of tourism. Future research could consider use of other climate change indicators other than rainfall and temperature in assessing climate change impacts.
\end{abstract}

Keywords: Climate Change, Tourism Sustainability, Maasai Mara Game Reserve

*Corresponding author: Laban Kipkemoi Rotich; E-mail: sirlurburn@gmail.com DOI: https://doi.org/10.37227/ITHJ-2020-02-27

\section{Introduction}

The more water molecules are in the environment, the hotter it gets (Sarah A. Browne and Len M. hunt, 2007), the result of climate change, because the sun's rays (short-wave radiation) enter the environment and the water that warms the surface is returned to the environment where natural emissions such as carbon dioxide $\left(\mathrm{CO}_{2}\right)$ and methane $\left(\mathrm{CH}_{4}\right)$ are absorbed. Water vapor, $\mathrm{CO}_{2}$ and other natural gasses help the Earth's climate through its heat capture and isolation, keeping the earth's surface temperature at 33 $\circ \mathrm{C}$ warmer than if it were and delivering sufficient heat over Earth's lifetime (IPCC, 2001).

Although the invention of agriculture greenhouse gas emission increased, the industry revolution that started around 1750 marked the beginning of a time when truly 
large amounts of $\mathrm{CO} 2$ and $\mathrm{CH} 4$ were added to the atmosphere (Sarah A. Browne and Len M. Hunt, 2007). In pre-industrial times, atmospheric $\mathrm{CO} 2$ rose by $31 \%$ due to the combustion of fossil fuels (charcoal, petroleum and gas) and forests converted to nonforestry circumstances (deforestation contrasts with viable forest harvesting and regeneration), as well as draining wetlands (IPCC, 2001). The increased concentrations of greenhouse gases keep more heat energy in the lower atmosphere, which increases temperature and alters precipitation (IPCC 2001). The results are climate change.

Climate is usually described as the average moment over a period, representing the circumstances that one would predict at a particular location and moment (Scott, Gossling and Hall, 2005). Climate is generally described in a limited sense as the average weather or more rigorously as the statistical description in terms of the average and varying amounts over a period of several months to thousands or million years. Cater, Garrod and Low (2015) describes climate change as a change in the worldwide average long-term weather. The classical period for these variables to be averaged is 30 years. Surface factors, like temperature, rainfall and wind, are the most frequently appropriate amounts. Climate in a broader context is the situation including the climatic system's statistical description (IPCC 2013).

Climate change is due to humans' activities of burning fossil fuels, which changes the atmosphere of the Earth. Carbon dioxide (CO2) and other greenhouse gases in the atmosphere have been measured and recorded and have shown to increase since preindustrial times. For decades to millennia, Green House Gases (GHGs) emitted through human operations stay in the environment and are certainly going to continue to increase in concentrations (EPA, 2011). Increasing GHGs tends to warm the world as a result of the modifications in weather patterns and circumstances, such as increasing drought frequencies and floods, erratic precipitation patterns and increasing temperatures.

During the last ten years, the problem of climate change and its relationships with tourism have been a problem for a quarter of a century and research in this field has intensified (Becken, 2010). Tourism is a very sensitive financial area comparable to agriculture, insurance, power and transportation due to its close links with the environment and the climate itself (Simpson, Gössling, Scott, Hall, and Gladin, 2008). The physical and scientific impacts of climate change present a number of major difficulties for tourism in terms of its effect on companies, destinations, infrastructure and resources, areas producing tourism, competitiveness, tourism flows and behavior, and adaptation and mitigation (Hall and Higham, 2005) and presently sustainability of tourism in the advent of climatic changes. The social, financial and environmental effects of climate change are not understood in specific terms but in general terms that the study investigates.

Continuous relations between climate and tourism are even stronger for coastal tourism, mountain tourism and nature tourism (Rayamajhi, 2012). The connection between climate change and tourism involves complicated, two-way relationships. Tourism on the one side, adds to the changing environment (Nicholls, 2006). Tourism specifically the travel sector contributes to climate change through greenhouse gas (GHG) emissions, including carbon dioxide, $\mathrm{CH} 4$, nitrous oxides (NOx), hydro fluorocarbones (HFCs) and sulfide hexafluoride (SF6), to climate change (Gossling and Hall, 2005). On the other hand, climate change undoubtedly influences the tourism industry considerably (Gössling and Hall, 2006). Unfortunately, fewer research has been conducted in the tourism sector on climate change and inadequate research has been done (Lise and Tol, 2002) prompting this study. This could be a consequence of the tourism industry's rather mild contribution to $\mathrm{CO} 2$ emissions. 
In the selection of location and tourist expenditure, the climate describes the duration and quality of tourist season and plays a significant role. Tourism is strongly connected to the natural environment in many locations especially for nature based tourism. Climate change impacts a broad variety of environmental assets, such as snow circumstances, wilderness and biological diversity, water levels and quality, which are essential tourism attractions. Climate change also plays a key role in environmental circumstances that can prevent visitors, for instance jellyfish, algae blooms and extreme occurrences, such as tropical cyclones, from infections, wildfires, insect or waterborne pests (CCT, 2008). Therefore, climate represents a key and crucial factor for the tourism industry especially in Kenya.

Climate change also has a significant impact on the tourism sector, mainly because of its influence on tourism destination attractions and tourist flows (Lise and Tol, 2002). It is important to have this complicated relation of climate change to tourism and its causes and implications (Berrittella, Bigano, Roson and Tol, 2006). It should be stressed, however, that not all operations, areas and destinations have equal financial, social and environmental implications (Shaw and Loomis, 2008). Flooding, storms, and drought would interfere with tourism. Lake Nakuru National Park in Kenya for instance has some of its administrative offices submerged with water due to rising water levels with climate change as a likely cause. The consequences of climate change would incapacitate the sustainability of the tourism industry.

While climate change remains a major media and political problem, it is not yet open for scientific dispute to the truth of climate change. The IPCC's most recently published study on climate change physical science shows that climate system warming is unambiguous and many of the modifications observed have been unprecedented since the 1950s over centuries to thousands (IPCC, 2013). All these observations point out that climate change is happening. Therefore, what is not clearly known are the implications of these climatic changes on the sustainability of the tourism industry.

In addition, extensive drops in glaciers and ice caps and warming of ocean surface temperatures have led to an increase in sea level of $1.8 \mathrm{~mm}$ per year from 1961 to 2003 and roughly $3.1 \mathrm{~mm}$ per year from 1993 to 2003 (IPCC, 2007). These are clear indicators of climatic changes. On every continent there has been a biological reaction between ecosystems and individual species. Climate changes are expected to proceed with various impacts on the tourism industry, and the sustainability of the tourism industry during the onset of climate change is of major significance to the present research. The question is will climate change allow the tourism industry to be more or less sustainable. Most importantly, it essential to evaluate the tourism industry's readiness to address climate change and the problems that arise while exploiting opportunities posed by climate change.

\section{Literature Review}

The first to offer a definite definition of human-induced climate change as a significant environmental issue has also been seen by the World Climate Change Conference, which has also recognized climate change as an independent government issue for which environmental policies are to be resolved (Vlassopoulos, 2012). Cater, Garrod and Low (2015) describe climate change as changes to the worldwide average long-term weather. Climate change refers to the long-term shift in weather conditions, for example, over decades to millions over millions of years, over the statistical distribution of temperature and precipitation (Rahman, 2013). 
Climate change interests and concerns have lately become widespread and a worldwide political problem (Scott \& Becken, 2010). In addition, in the field of tourism studies, it also receives important consideration (Gossling and Peeters, 2007). Indeed, Buckley and Shakeela (2013) say that climate change is one of the primary dangers to be faced by the tourism sector. Climate changes are now acknowledged as an important social and environmental problem for the worldwide population and its resources by the majority of governments and researchers around the globe (Viner, Nichollis and Amelung, 2011). Figure 1, below shows the evolution of the climate change discourse.

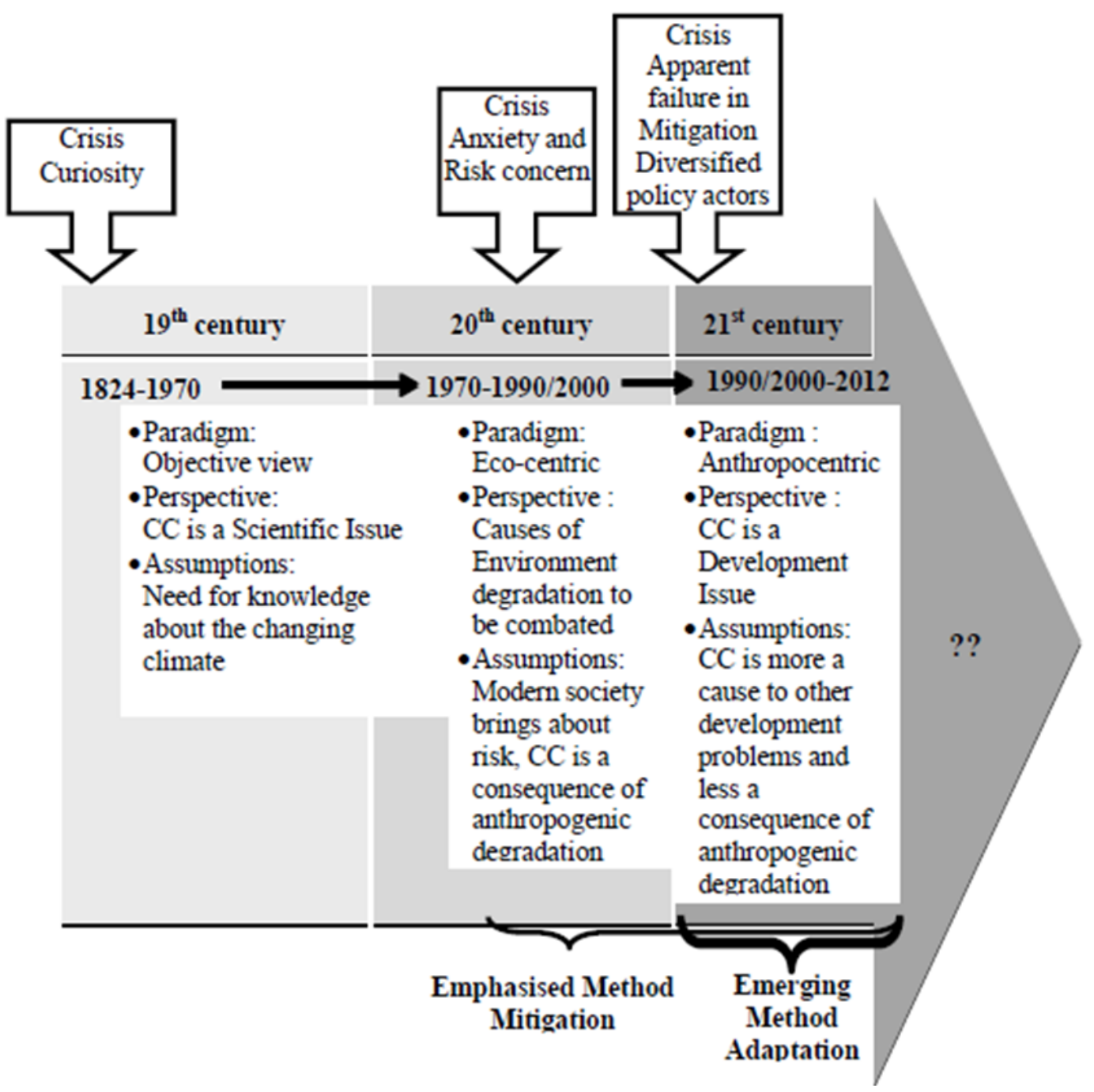

Figure 1: Structure of the revolution of the Climate Change discourse.

Source: Rahman (2013).

\section{Evolution of the Climate Change Discourse}

Analysis of climate change history reveals that it has spread over three hundred years and apparently over the years has undergone transformations (Rahman, 2013). The climate change history shows that it turned out to be a public agenda from an exclusively science point of view which now tends more towards developing (Rahman, 2013). Since 
the start of the 19th century, the issue was exclusively debated in the scientific community at the end of the 20th century (Vlassopoulos, 2012).

Since then, on the one side, climate change believers have demonstrated that human operations have reached an alarming state and posed a critical danger to physical and socio-economic buildings on the other, and on the other hand sceptics have provided reasonable proof to disqualify the anthropogenic characteristics of climate change (Rahman, 2013). Analysis of the climate change speech demonstrates that the problem has been caused by' environmental degradation' from its original view of a "full science problem' and in latest times it has gained in scope that goes beyond environmental degradation (Vlassopoulos, 2012).

The increase of the burning of fossil fuel and land-use modifications emit greenhouse gases into the atmosphere of the Earth. Pang, McKercher and Prideaux (2013) claim that tourism is recognized as a major contributor to climate change by the industry, as both a victim and a vector of climate change. These greenhouse gasses contain carbon dioxide (CO2), methane (CH4).

The increase in these gases has triggered an increase of the heat from the sun, which would be usually radiated back into space, retained in the earth's atmosphere. This rise in temperature has resulted to climate change and a greenhouse impact. Changes in the cloud cover and precipitation especially over the earth, melts of ice caps and glaciers and reduces snow cover, ocean temperature rises and sea water acidity owing to sea water absorbing heat and carbon dioxide in the atmosphere are the primary features of climate change.

The sort, frequencies, and intensity of occurrences such as tropical cyclones, floods, droughts, and heavy precipitation is anticipated to increase with comparatively tiny average rates due to global warming induced by climate change. Ayana, Ceccato, Fisher and DeFries (2016) claim that Africa's main horn's drought frequency has increased every 6 years from once to once every 3 years and has been a major contributor to the rise of disputes based on resources in the area. This would lead to a variety of challenges as well as opportunities for the tourism industry that is nature based and dependent on climatic conditions. Some of the effects of such climatic changes have already started being experienced by the tourism industry. With climatic changes already happening, it is not clearly known whether the tourism industry will be sustainable.

\section{Global Tourism Industry and Climate Change}

Climate change is one of the world's most important problems in the 20th century (Jamal \& Watt, 2011). Awareness, debates and discussion on the worldwide effects of climate change have been growing continuously since the early 1990s. Indeed (Zeppel 2011) notes that, as part of a UN Framework Convention on Climate Change (UNFCCC) established the Kyoto Protocol in 1992 for reducing emissions, four worldwide evaluation reports (1990, 1995, $2001 \& 2007)$ had been published by the Intergovernmental Panel on Climate Change (IPCC).

Weaver (2011) states that through many distinct processes the tourism industry has been affected by climate change, including: modifications in the environment and human reactions in the nations of origin and the tourist destinations (Moore 2010), mitigation and offset measures (Gössling 2010), and adjustments to travel patterns due in part to increased economic and social transport expenses (Nawijn and Peeters 2010). Globally, governments have tried to create an extensive, integrated climate change management regulatory scheme, the Kyoto Protocol (Keohane \& Victor, 2011). For developed countries such as Kenya, the Government and Non-Governmental organizations have come to the realization 
of climate change implications and even developed strategies to counter it. It is not clear whether these strategies are effective and have yielded intended results.

\section{Climate Change and Sustainability of Tourism}

In 1987, the Committee on the Environment and Development defined sustainable development as "a system that addresses today's requirements without affecting future generations ' capacity to satisfy their own requirements" (Gonzales, 2016). The term viable tourism, ecotourism and ethical tourism are interchangeably employed (Cater et al., 2015). It is usually described as all types of tourism aimed at building beneficial interaction and truly positive experiences for all stakeholders (Farid, Hakimian, Nair, and Ismail, 2016).

UNEP (2012) describes sustainable tourism as tourism, taking complete account, in the context of visiting, industrial, environment and host groups, of its present and future financial, social and environmental effects while responding to their requirements. In order to encourage (more) viable tourism, the UNWTO has created rules and management methods for all kinds of tourism in all kinds of locations.

The notion of sustainable tourism, namely financial, social and environmental stability, has since developed and extended to the three dimensions of sustainable development. In order to ensure its long-term sustainability (UNWTO, 2005), sustainable principles should relate to the environmental, financial, and social-cultural elements of tourism growth and a proper balance should be developed among the three dimensions. To ensure sustainability, an adequate balance is needed between the financial, social and environmental elements of tourism. However, it is also stated that tourism can never be entirely viable but that "sustainable tourism growth is an ongoing enhancement method" (Gonzales, 2016). Scott and Becken (2010) claim that the main challenge for viable tourism in the 21 st century is climate change. UNEP \& UNWTO (2005) claims that viable tourism should:

(a) Optimize the use of environment resources that are the main component in developing tourism, maintain vital environment-related procedures and help preserve natural and biodiversity heritage.

b) Respect the socio-cultural genuine nature of host groups, preserve and contribute towards an inter-cultural comprehension and tolerance of their cultural heritage and traditional values.

c) Ensure viable, long-term economic operations, providing socio-economic benefits to all stakeholders that are fairly distributed, including stable employment and income-earning opportunities and social services to host communities, and contributing to poverty alleviation.

\section{Research Methodology}

The study adopted explanatory research design. The target population was 169,220 household in Narok County, 300 tourists and 18 experts. The sample size was 507 respondents comprising of 399 households, 90 tourists and 18 experts selected by simple random sampling, convenience sampling and snowball sampling respectively. Key informant interviews were used to collect data from climate change experts and tourists. These data were analyzed qualitatively using content analysis. Structured questionnaires collected data from the host community which was analyzed using Pearson product moment of correlation, linear and multiple regressions. Data analyses were done through quantitative techniques of descriptive and inferential statistics with the aid of SPSS V.23. Based on the regression model (R squared) of .395 shows that $39.5 \%$ of the variation in tourism sustainability in MMNGR can be explained by availability of natural resources. 


\section{Results and Analysis}

\section{Effects of Climate change on tourism sustainability}

Local community members living adjacent to MMNGR were requested to indicate their opinion on the effects of climate change on natural resources and tourism sustainability using a five-point Likert Scale. A total of 32 statements were used to determine the community member's perception on tourism sustainability and responses summarized using a 5-point Likert Scale. Descriptive statistics, mean and standard deviation were used to summarize the responses as presented in Table 1.

Most of the respondents $153(51.9 \%)$ agreed that drought and flooding scenarios appear to have increased in the reserve affecting wildlife population, with $23.1 \%$ undecided and $25.1 \%$ disagreed $(M=3.23 ; S D=1.07)$. Also, majority of the respondents $149(50.5 \%)$ agreed that flooding and drought scenarios in the reserve seem to result in loss of biodiversity, with $32.9 \%$ undecided and $16.6 \%$ disagreed $(M=3.43 ; S D=0.91)$.

Table 1: Effects of Climate Change on Tourism Sustainability

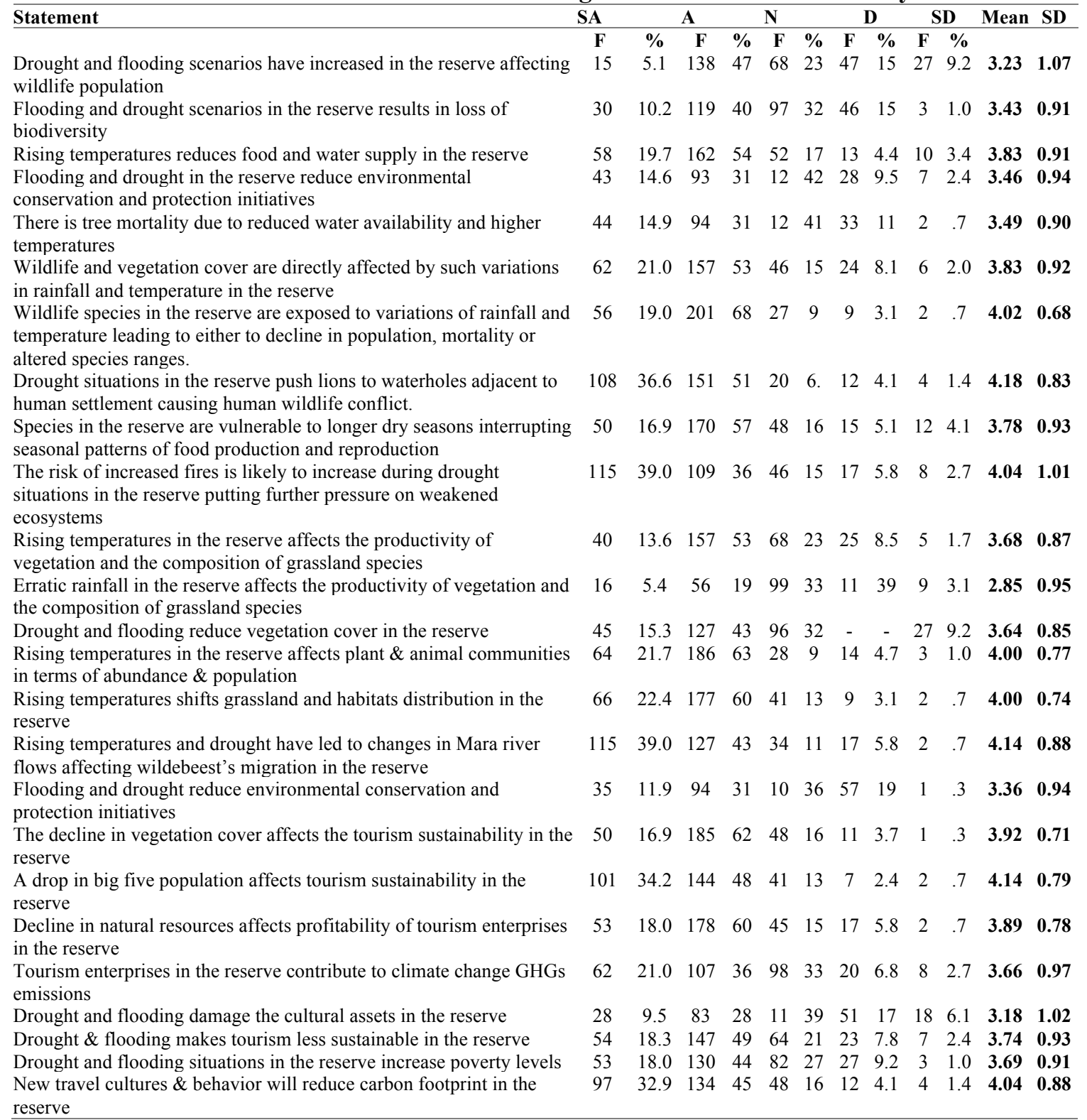




\begin{tabular}{|c|c|c|c|c|c|c|c|c|c|c|c|c|}
\hline $\begin{array}{l}\text { Rising temperatures increases the cost of operation for example } \\
\text { heating and cooling }\end{array}$ & 58 & 19.7 & 152 & 51 & 69 & 23 & 16 & 5.4 & & & 3.85 & 0.79 \\
\hline $\begin{array}{l}\text { Rapid rainfall patterns reduce the range of tourism recreational } \\
\text { activities in the reserve }\end{array}$ & 89 & 30.2 & 154 & 52 & 39 & 13 & 10 & 3.4 & 3 & 1.0 & 4.07 & 0.81 \\
\hline Drought and flooding in the reserve reduce the length of tourists stay & 94 & 31.9 & 145 & 49 & 40 & 13 & 13 & 4.4 & 3 & 1.0 & 4.06 & 0.85 \\
\hline $\begin{array}{l}\text { Drought and flooding in the reserve reduce the profitability of tourism } \\
\text { enterprises }\end{array}$ & 57 & 19.3 & 135 & 45 & 87 & 29 & 15 & 5.1 & 1 & .3 & 3.79 & 0.82 \\
\hline Flooding situations in the reserve damages the infrastructure & 142 & 48.1 & 116 & 39 & 25 & 8 & 9 & 3.1 & 3 & 1.0 & 4.31 & 0.83 \\
\hline $\begin{array}{l}\text { Flooding and drought scenarios in the reserve reduce the community's } \\
\text { ability to create wealth thorough tourism }\end{array}$ & 59 & 20.0 & 136 & 46 & 80 & 27 & 17 & 5.8 & 3 & 1.0 & 3.78 & 0.87 \\
\hline Flooding inhibits accessibility of tourist destinations in the reserve & 120 & 40.7 & 124 & 42 & 32 & 10 & 13 & 4.4 & 6 & 2.0 & 4.15 & 0.92 \\
\hline Mean & & & & & & & & & & & 3.79 & 0.44 \\
\hline
\end{tabular}

Most of the respondents 220 (74.6\%) agreed that rising temperature is likely to be reducing food and water supply in the reserve with $72.5 \%$ undecided and $7.8 \%$ disagreed. Also, majority $219(74.2 \%)$ of the respondents agreed that wildlife as well as vegetation cover seem to be directly affected by such variations in rainfall and temperature with $15.6 \%$ undecided and $10.1 \%$ disagreed $(M=3.83 ; S D=0.92)$. In addition, majority of the respondents $136(46.1 \%)$ agreed that flooding and drought in the reserve appear to reduce environmental conservation and protection initiatives with $36.6 \%$ undecided and $19.6 \%$ disagreed $(M=3.36 ; S D=0.94)$.

Furthermore, most of the respondents $138(46.8 \%)$ agreed that it is likely that tree mortality in the reserve is due to reduced water availability and higher temperatures, with $41.4 \%$ undecided and $11.9 \%$ disagreed $(M=3.49 ; S D=0.90)$. Moreover, most of the respondents $257(87.1 \%)$ agreed that wildlife species in the reserve seem exposed to variations of rainfall and temperature leading to either to decline in population, mortality or altered species ranges, with $3.8 \%$ disagreed and $9.2 \%$ undecided $(M=4.02 ; S D=0.68)$. What is more, most of the respondents $259(87.8 \%)$ agreed that drought situations in the reserve appear to push lions to waterholes adjacent to human settlement causing human wildlife conflict, with $6.8 \%$ undecided and $5.5 \%$ disagreed $(M=4.18 ; \quad S D=0.83)$. Furthermore, majority $220(74.5 \%)$ of the respondents agreed gave the impression that wildlife species in the reserve are vulnerable to longer dry seasons interrupting seasonal patterns of food production and reproduction, with $16.3 \%$ undecided and $9.2 \%$ disagreed $(\mathrm{M}=3.78 ; \mathrm{SD}=0.93)$.

Most of the respondents $224(75.9 \%)$ agreed that the risk of increased fires is likely to increase during drought situations in the reserve putting further pressure on weakened ecosystems with $15.6 \%$ undecided and $8.5 \%$ disagreed. Also, majority of the respondents $231(78.3 \%)$ agreed that new travel cultures \& behavior would reduce carbon footprint in the reserve with $16.3 \%$ undecided and $5.5 \%$ disagreed $(\mathrm{M}=4.04 ; \mathrm{SD}=0.88)$. In addition, majority of the respondents $197(66.8 \%)$ agreed that rising temperatures in the reserve appear to affect the productivity of vegetation and the composition of grassland species, with $23.1 \%$ undecided and $10.2 \%$ disagreed $(\mathrm{M}=3.68 ; \mathrm{SD}=0.87)$.

Most of the respondents $172(58.4 \%)$ agreed that drought and flooding reduce vegetation cover in the reserve, with $32.5 \%$ undecided and $9.2 \%$ disagreed $(\mathrm{M}=3.64$; $\mathrm{SD}=0.84)$. Also, from the study $250(84.8 \%)$ of the respondents agreed that rising temperatures in the reserve appear to affect plant \& animal communities in terms of abundance $\&$ population with $9.5 \%$ undecided and $5.7 \%$ disagreed. In addition, most of the respondents $243(82.4 \%)$ agreed that rising temperatures seem to shift grassland and habitats distribution in the reserve with $13.9 \%$ undecided and $3.8 \%$ disagreed $(M=4.00$; $\mathrm{SD}=0.7)$. Furthermore, majority of the community members $242(82.1 \%)$ agreed that rising temperatures and drought have likely led to changes in Mara river flows affecting wildebeest's migration in the reserve with $11.5 \%$ undecided and $6.5 \%$ disagreed $(\mathrm{M}=4.14$; 
$\mathrm{SD}=0.88)$. Moreover, most of the respondents $245(83 \%)$ agreed that a drop in the big five population seems to affect tourism sustainability in the reserve with $13.9 \%$ undecided and $3.1 \%$ disagreed $(\mathrm{M}=4.14 ; \mathrm{SD}=0.79)$. What is more, majority of the community members $235(79.6 \%)$ agreed that it appears there was a decline in vegetation cover that affects tourism sustainability in the reserve with $36.6 \%$ undecided and $19.6 \%$ disagreed $(\mathrm{M}=3.92$; $\mathrm{SD}=0.71)$.

Also, most of the respondents $231(78.3 \%)$ agreed that decline in natural resources affects profitability of tourism enterprises in the reserve with $15.3 \%$ undecided and $6.5 \%$ disagreed $(\mathrm{M}=3.89 ; \mathrm{SD}=0.78$. $)$. In addition, majority of the respondents $169(57.3 \%)$ agreed that and tourism enterprises in the reserve seem to contribute to climate change through GHGs emissions with 33.2 undecided and 9.5\% disagreed $(\mathrm{M}=3.66 ; \mathrm{SD}=0.97)$.

Majority of the community members $201(68.1 \%)$ agreed that drought \& flooding appears to make tourism less sustainable in the reserve with $21.7 \%$ undecided and $10.2 \%$ disagreed $(\mathrm{M}=3.74 ; \mathrm{SD}=0.93)$. Also, most of the respondents $183(62.1 \%)$ agreed that drought and flooding situations likely increase poverty levels with $27.8 \%$ undecided and $10.2 \%$ disagreed $(\mathrm{M}=3.69 ; \mathrm{SD}=0.91)$. Furthermore, majority of the community members $210(71.2 \%)$ agreed that rising temperatures increases the cost of operation for example heating and cooling in the reserve with $23.4 \%$ undecided $(\mathrm{M}=3.85 ; \mathrm{SD}=0.79)$. Moreover, majority of the community members $243(82.4 \%)$ agreed that rapid rainfall patterns reduce the range of tourism recreational activities in the reserve with $13.2 \%$ undecided and $4.4 \%$ disagreed $(\mathrm{M}=4.07 ; \mathrm{SD}=0.81)$. What is more is that most of the respondents $239(81.1 \%)$ agreed that drought and flooding in the reserve seem to reduce the length of tourists stay with $13.6 \%$ undecided and $5.4 \%$ disagreed $(\mathrm{M}=4.06 ; \mathrm{SD}=0.85)$.

Majority of the community members $192(65.1 \%)$ agreed that drought and flooding in the reserve likely reduce the profitability of tourism enterprises in the reserve with $29.5 \%$ undecided and 5.4\% undecided and 5.4\% disagreed $(\mathrm{M}=3.79 ; \mathrm{SD}=0.82)$. Also, most of the respondents $258(87.4 \%)$ agreed that flooding situations in the reserve appear to damage the infrastructure with $8.5 \%$ undecided and $4.1 \%$ disagreed $(\mathrm{M}=4.31 ; \mathrm{SD}=0.83)$. In addition, majority of the community members 195 (66.1\%) agreed that flooding and drought scenarios in the reserve appear to reduce the community's ability to create wealth through tourism with $27.1 \%$ undecided and $6.8 \%$ disagreed $(\mathrm{M}=3.78 ; \mathrm{SD}=0.87)$.

Furthermore, most of the respondents $244(82.7 \%)$ agreed that flooding seems to inhibit accessibility of tourist destinations in the reserve with $10.8 \%$ undecided and $6.4 \%$ disagreed $(\mathrm{M}=4.15 ; \mathrm{SD}=0.92)$. Moreover, the community members were not sure whether drought and flooding damage the cultural assets in the reserve with 111 (37.6\%) agreed, $39.0 \%$ undecided and $23.4 \%$ disagreed $(\mathrm{M}=3.18 ; \mathrm{SD}=1.02)$. Finally, most of the respondents $124(42.1 \%)$ disagreed that erratic rainfall in the reserve affects the productivity of vegetation and the composition of grassland species with $33.6 \%$ undecided and $24.4 \%$ agreed $(\mathrm{M}=2.85 ; \mathrm{SD}=0.95)$.

Based on the regression model and Table 1 below, the coefficient of determination (R squared) of .395 shows that $39.5 \%$ of the variation in tourism sustainability in Maasai Mara National Game Reserve (MMNGR) can be explained by climate change. The adjusted $\mathrm{R}$ square of .392 depicts that all the climate change in exclusion of the constant variable explained the variation in tourism sustainability in MMNGR by $39.2 \%$ the remaining percentage can be explained by other factors excluded from the model. The standard error of estimate (.449) shows a deviation of the independent variables from the line of best fit. 
Table 1: Model Summary

\begin{tabular}{|c|c|c|c|c|c|c|c|c|c|}
\hline \multirow[t]{2}{*}{ Model } & \multirow[t]{2}{*}{$\mathrm{R}$} & \multirow{2}{*}{$\begin{array}{c}\mathrm{R} \\
\text { Square }\end{array}$} & \multirow{2}{*}{$\begin{array}{l}\text { Adjusted } \\
\text { R Square }\end{array}$} & \multirow{2}{*}{$\begin{array}{l}\text { Std. Error } \\
\text { of the } \\
\text { Estimate }\end{array}$} & \multicolumn{5}{|c|}{ Change Statistics } \\
\hline & & & & & $\begin{array}{l}\text { R Square } \\
\text { Change }\end{array}$ & F Change & df1 & $\mathrm{df} 2$ & $\begin{array}{c}\text { Sig. F } \\
\text { Change }\end{array}$ \\
\hline 1 & $.628^{a}$ & .395 & .392 & .44919 & .395 & 190.950 & & 293 & .000 \\
\hline
\end{tabular}

The regression model with climate change as a predictor was significant $(F=190.95, p$ value $=0.000$ ) shows that there is a significant relationship between climate change and tourism sustainability in MMNGR and at least the slope ( $\beta$ coefficient) is not zero as shown in table 2.

Table 2: Climate change ANOVA

\begin{tabular}{llrrrrl}
\hline Model & $\begin{array}{c}\text { Sum of } \\
\text { Squares }\end{array}$ & \multicolumn{1}{c}{ df } & $\begin{array}{c}\text { Mean } \\
\text { Square }\end{array}$ & F & \multicolumn{1}{l}{ Sig. } \\
\hline 1 & Regression & 38.528 & 1 & 38.528 & 190.950 & $.000^{\mathrm{b}}$ \\
& Residual & 59.118 & 293 & .202 & & \\
& Total & 97.646 & 294 & & & \\
\hline
\end{tabular}

a. Dependent Variable: Sustainability

b. Predictors: (Constant), Climate

Therefore, it can be implied that there is a significant relationship between tourism sustainability in MMNGR and climate change. Thus, rejecting the null hypothesis as predicted that there is no significant relationship between climate change and tourism sustainability in MMNGR. The study hypothesized that there is no significant influence of climate change on tourism sustainability in MMNGR.

From the interviews, the tourists acknowledged that they were received well by the local communities during their visits to MMNGR. Most of the interviewed tourists reported that the local community reception is warmly, friendly and welcoming. "The Maasai's are friendlier and received us with songs, and other entertaining activities", testified one of the tourist. The tourists were generally happy, impressed with the friendly reception. "The reception was great and so much interesting and admirable" lamented one of the interviewed tourists.

Furthermore, another interviewed tourist reported that "the reception was exemplary, friendly and welcoming, warmly, with love and care as their own. I was received by traditional songs, activities and ate indigenous food. During my visits to one of the local community's manyatta the reception was awesome and exceptional. The reception was incompatible for the all times I visited and won't stop visiting all the time".

From the interview results, it was established that the nature of the interaction with the local communities was good. The interview results also established that the local communities were proud about their culture. The tourists rated the nature of the interaction with the local communities to be great, able to learn about the Maasai culture, the beads items and importance of wildlife in their life. Some of the tourists interacted with local communities through various activities such as the Maasai's lifestyle, entertainment with local songs, given cultural foods and drinks. The interaction was diverse and based on cultural significance of beadings and benefits they have gained from tourism.

One of the tourist reported that "the interaction was so much inclusive and therefore was able to learn a lot about their culture, lifestyle and their passion for wildlife. 
My interaction with the local was one of its kind, the community was so friendly, kind and appear more attractive to the tourists. I was able to learn a lot about the community through their lifestyle, cultural activities, beads and their perception about wildlife."

"My interaction with the local community remained an indelible one because I was able to acquire more information on lifestyles and culture" lamented another tourist. "During my all visits to the MMNGR I have visited the Manyattas where I was able to exchange a lot with the locals about their culture, I was given a lot of milk to drink and involved in beading activities" reported another interviewed tourists. The tourists were able to learn and acquired more information about Maasai lifestyles, cultural activities, beads their perception on wildlife conservation. "I was able to learn a lot about the communities through their lifestyle, cultural activities, beads and their perception about wildlife" another interviewed tourist said.

\section{Discussions and Implications}

From the study findings, the community identified the effects of climate change tourism sustainability occurs through drought, flooding and rising temperatures that reduce food and water supply in the reserve. Furthermore, from the interview results, it was established that the tourist had varied opinions on wildlife/vegetation conservation initiatives. Based on the results, it is highly likely that wildlife and vegetation has reduced due to combined cause factors including climate change effects hence negatively influencing the sustainability of tourism. Additionally, it appears a number of sustainable tourism initiatives are adopted.

There exists a dire need for more sustainable tourism actions to be carried out by Narok County and National government as well as tourism stakeholders in order to restore the wildlife/vegetation conservation as well as protection in order to safeguard sustainability of tourism into the future. What is more is that, MMNGR stakeholders have the willingness and desire to protect wildlife and vegetation. Sufficient, permanent initiatives need to be in place to cater for a better wildlife and vegetation. The Maasai Mara Game Reserve stakeholders have initiated plans, activities that aim at ensuring sustainable tourism. Wildlife/Vegetation conservation initiates in MMNGR should be a top priority as the reserve accounts for $30 \%$ of the Country's wildlife resource and a significant source of wealth for the country.

The interview results among the tourists indicated the management of Maasai Mara National Game Reserve had adaptation and mitigation strategies to overcome the changing climatic conditions. This is essential in ensuring sustainability of the tourism industry. The adaptation and mitigation strategies to climate change conditions are vital for wildlife tourism attraction sites to continue receiving visitors as well as guests. There exists a need for National and Narok County Governments to mainstream sustainable tourism strategies as well as initiatives into their strategic tourism development plans.

\section{Conclusions}

There is a positive significant relationship between climate change and tourism sustainability in Maasai Mara National Game Reserve (MMNGR). There exists a strong possibility that climatic changes would impact the sustainability of tourism by reducing the benefits that local Maasai communities derive from tourism. For instance, due to reduced wildlife population as a result of climatic changes among other factors, visitor numbers in the reserve could decline hence cutting down local employment in the tourism facilities within the game reserve. The study recommends that Kenya Wildlife Service (KWS) 
should consider procuring a real time technological tool to monitor wildlife dynamics in terms of their population and distribution under changing climatic conditions. Additionally, the same technology should conduct real time monitoring of vegetation abundance and distribution in protected areas in order to ensure availability of quality vegetation for wild life. These will further ensure adequate Wildlife populations to sustain visitor numbers hence guarantee a source of livelihood for the host community and ensuring tourism sustainability into the future.

\section{Research Limitations and Future Directions}

Questionnaires were used for data collection where prompting and probing are impossible and this limits the scope of answers and the possibility of getting additional data. Furthermore, interviews consume much time in terms of preparation, scheduling, writing letters and booking appointments in a busy working environment. Also, key informant interviews was conducted where it is not easy to prove that the interviewees are, in fact, knowledgeable and informed and that they are representative of their peers in their information and recommendations. This study sought to establish the mediating effects of natural resources availability on the relationship between climate change and tourism sustainability in Maasai Mara National Game Reserve. Future climate change and related studies should consider conducting their studies on other game reserves or protected areas (PA'S) in order to draw comparisons. There is a need to use other climate change indicators other than rainfall and temperature that was used in this study.

\section{References}

Ayana, E. K. (2016). Examining the relationship between environmental factors and conflict in pastoralist areas of East Africa. Science of the Total Environment, 601-611.

Amelung, B., Nicholls, S., \& Viner, D. (2007). Implications of global climate change for tourism flows and seasonality. Journal of Travel Research, 45(3), 285-296.

Becken, S. (2010). The importance of climate and weather for tourism. New Zealand: LEAP.

Berrittella, M., Bigano, A., Roson, R. and Tol, R.S.J. (2006). A General Equilibrium Analysis of Climate Change Impacts on Tourism. Tourism Management, 27(5), 913-924.

Buckley, R.C. and Shakeela, A. (2013). "The vulnerability of tourism and recreation to climate change", in Seastedt, T. (Ed.), Climate Vulnerability: Understanding and Addressing Threats to Essential Resources. Elsevier Oxford, 223-228.

Cater, C., Garrod, B. and Low, T. (2015). The Encyclopedia of Sustainable Tourism. Oxfordshire: CABI.

Chapman, L. (2007). Transport and Climate Change. A Review, Journal of Transport Geography, $15(5), 354-367$

Gössling, S. (2010). Sustainable tourism development in developing countries: Some aspects of energy use. Journal of Sustainable Tourism, 8(5), 410-425.

Gossling, S. and Peeters, P. (2007). It does not harm the environment! An analysis of industry discourses on tourism, air travel and the environment. Journal of Sustainable Tourism, 5(4), 402-417.

Farid, H., Hakimian, F., Nair, V., Nair, P. K., \& Ismail, N. (2016). Trend of research on sustainable tourism and climate change in 21st century. Worldwide Hospitality and Tourism Themes. 8(5), 516-533.

Hall, C. M. and Higham, J. (2005). Tourism, Recreation and Climate Change. Clevedon: Channelview Publications.

IPCC, 2013: Climate Change 2013: The Physical Science Basis. Contribution of Working Group I to the Fifth Assessment Report of the Intergovernmental Panel on Climate Change [Stocker, T.F., D. Qin, G.-K. Plattner, M. Tignor, S.K. Allen, J. Boschung, A. Nauels, Y. 
Xia, V. Bex and P.M. Midgley (eds.)]. Cambridge University Press, Cambridge, United Kingdom and New York, NY, USA, 1535 pp

IPCC. (2001). Climate Change 2001 - Impacts, Adaptation and Vulnerability: Summary for Policy Makers and Technical Summary of the Working Group II Report. Geneva: IPCC.

IPCC. (2007). The Physical Science Basis - Contribution of Working Group i to the Fourth Assessment Report of the Intergovernmental Panel on Climate Change. Cambridge and New York: University Press Cambridge.

Jamal, T. A. (2011). Climate change pedagogy and performative action. Journal of Sustainable, 571-588.

Lise, W. and Tol, R. S. J. (2002). Impact of Climate on Tourist Demand. Climate Change, 55(4), 429-449.

Moore, W. (2010). The impact of climate change on Caribbean tourism demand. Current Issues in Tourism, 495-505.

Nawijn, J., and P.M. Peeters. (2010). Travelling “green": Is tourists' happiness at stake? Current Issues in Tourism, 13(4), 381-392.

Nicholls S. (2006). Climate Change, Tourism and Outdoor Recreation in Europe. Managing Leisure, 11(3), 151-163.

Pang, S. F., McKercher, B. \& Prideaux, B. (2013). Climate change and tourism: An overview. Asia Pacific Journal of Tourism Research, 4-20.

Rahman, M. I. - U. (2013). Climate Change: A Theoretical Review. Interdisciplinary Description of Complex Systems, 1-13.

Rayamajhi, S. (2012). Linkage between Tourism and Climate Change: A case study of the Perceptions of Stakeholders along the Annapurna Trekking Trail. Nepal Tourism and Development Review, 16.

Sarah A. Browne and Len M. Hunt. (2007). Climate change and nature-based tourism, outdoor recreation, and forestry in Ontario: Potential effects and adaptation Strategies. Ontario, Canada: Queen's Printer for Ontario.

Scott and Becken. (2010). Adapting to climate change and climate policy: Progress, problems and potentials. Journal of Sustainable Tourism, 18(3), 238-295.

Simpson, M.C., Gössling, S., Scott, D., Hall,C.M. and Gladin, E. (2008). Climate Change Adaptation and Mitigation in the Tourism Sector: Frameworks, Tools and Practices. Paris, France: Oxford University Press.

UNEP \& UNWTO. (2005). Making Tourism More Sustainable. A Guide for Policy Makers, 11-12.

UNEP. (2012). Making tourism more sustainable: a guide for policy makers. New York: UNEP.

United Nations Environment Programme (UNEP) and United Nations World Tourism Organization (UNWTO). (2008). Making Tourism More Sustainable - A Guide for Policy Makers. Paris and Madrid: UNEP and UNWTO.

UNWTO. (2008). Climate Change and Tourism - Responding to Global Challanges. Madrid: UNWTO.

Vlassopoulos, C. (2012). Competing definition of Climate Change and the post-Kyoto negotiations. International Journal of Climate Change Strategies and Management, 4(1) 104-118.

Weaver, D. (2011). Can sustainable tourism survive climate change? Journal of Sustainable Tourism, $19(1)$.

Zeppel, H. (2011). Climate Change and Global Tourism: A Research Compendium. Queensland: Australian Centre for Sustsainable Business and Development. 